\title{
História de capitalidade do Rio de Janeiro
}

\author{
Mauro Osorio da Silva ${ }^{1}$ \\ Maria Helena Versiani ${ }^{2}$
}

\begin{abstract}
Resumo
Este artigo trata do fato de a cidade do Rio de Janeiro ter se construído historicamente como o "eixo da capitalidade" do país ou como a sua "cidade-capital" (Argan, 1964). Na perspectiva de Argan, todos os países possuem uma cidade que é a sua referência internacional e que não necessariamente é também a sua Capital burocrática. Por exemplo, Nova York (em vez de Washington) para os Estados Unidos, e Sidney (em vez de Camberra) para a Austrália. Sendo assim, reconhecemos a cidade do Rio de Janeiro como a cidade-capital do Brasil, o que constitui um elemento-chave para o entendimento da trajetória da cidade e do estado do Rio de Janeiro, que interfere decisivamente no processo de definição de políticas públicas e de estratégias econômicas para a região. Duas questões orientam a análise aqui apresentada: 1) Quais experiências e condições históricas contribuíram para que a cidade do Rio de Janeiro despontasse como o eixo da capitalidade brasileira? 2) Como e por que essa condição de cidade-capital influenciou e ainda influencia a trajetória econômica da cidade e do estado do Rio de Janeiro?
\end{abstract}

Palavras-chave: Rio de Janeiro; Economia Regional; Capitalidade.

\section{Abstract}

This article addresses the fact that Rio de Janeiro had been constructed historically either as the "axis of the capitality" of the country or as its "capital city" (Argan, 1964). In Argan's view, all countries have a city that is its international standard and which is not necessarily its bureaucratic Capital. For example, New Your (instead of Washington) in America, and Sidney (instead of Camberra) regarding Australia. From this assumption, we recognize the city of Rio de Janeiro as the capital city of Brazil. This characteristic stands as a key element for understanding the trajectory of the city and the state of Rio de Janeiro, which decisively affect the definition of public policies and economic strategies for the region. Two questions guide the analysis presented here: 1) Which experiences and historical conditions have contributed for the city of Rio de Janeiro to appear as the hub of Brazilian capitality? 2) How and why this condition as capital city has influenced the economic history of the city and the state of Rio de Janeiro?

Keywords: Rio de Janeiro; Regional Economy; Capitality.

Este artigo trata de uma característica singular da cidade do Rio de Janeiro no cenário da Federação brasileira: o fato dela ter se construído historicamente como o "eixo da capitalidade" do país ou como a sua "cidade-capital", conforme expressões do historiador de arte e ex-prefeito de Roma, Giulio Argan (1964). Na perspectiva de Argan, todos os países possuem uma cidade que é a sua referência internacional e que não necessariamente é também a sua Capital burocrática. Assim, quando pensamos nos Estados Unidos, tendemos a pensar em Nova York e não em Washington; quando pensamos na Austrália, lembramos de Sidney e não de Camberra. Nas palavras da historiadora Marly Silva da Motta (2001:24), as cidades-capitais de Giulio Argan são “o lugar da política e da cultura, como núcleo da sociabilidade intelectual e da produção simbólica, representando, cada uma a sua maneira, o papel de foco da civilização, núcleo da modernidade, teatro do poder e lugar de memória”.

Filiados a essa premissa analítica, reconhecemos a cidade do Rio de Janeiro como a cidade-capital do Brasil. E tal característica, a nosso ver, coloca-se como um elementochave para o entendimento da trajetória da cidade e do estado do Rio de Janeiro, que

1 Mauro Osorio da Silva: Economista, doutor em Planejamento Urbano e Regional pelo Instituto de Pesquisa e Planejamento Urbano e Regional/UFRJ; professor da Faculdade Nacional de Direito da UFRJ; coordenador do Observatório de Estudos sobre 0 Rio de Janeiro, vinculado ao Programa de Mestrado em Direito e Instituições, da FND/UFRJ. mauroosorio@uol.com.br.

2 Maria Helena Versiani: Historiadora, doutora em História, Política e Bens Culturais pelo Centro de Pesquisa e Documentação de História Contemporânea do Brasil/FGV; pesquisadora do Museu da República; integrante do Grupo de Pesquisa Observatório de Estudos sobre o Rio de Janeiro, vinculado ao Programa de Mestrado em Direito e Instituições, da FND/UFRJ. m.versiani@ globo.com. 
interfere decisivamente no processo de definição de políticas públicas e de estratégias econômicas para a região.

Resumidamente, duas questões orientam a análise aqui apresentada:

1. Quais experiências e condições históricas contribuíram para que a cidade do Rio de Janeiro despontasse como o eixo da capitalidade brasileira?

2. Como e por que essa condição de cidade-capital influenciou e ainda influencia a trajetória econômica da cidade e do estado do Rio de Janeiro?

\section{O Rio de Janeiro nasce como eixo de logística nacional}

A cidade do Rio de Janeiro nasceu como fortificação militar, porto e centro da logística nacional. Segundo Carlos Lessa (2000a:68), a existência da Baía de Guanabara, com seu aspecto geográfico de "cofre-forte militar-naval", foi um fator fundamental para a decisão de Portugal de ocupá-la. E, efetivamente, ela serviu como elemento decisivo da defesa da nova Colônia e para a constituição da cidade como centro militar, porto e eixo de logística nacional.

A função da cidade como eixo de logística nacional teve início já durante os ciclos da prata (séculos XVI e XVII) e do ouro (século XVIII), uma vez que era o seu porto que articulava essas atividades com o mundo exterior. ${ }^{3}$

Entre os séculos XV a XVII, a prata foi a moeda de troca para o comércio europeu com o Oriente, sendo, portanto, essencial ao comércio de especiarias de Portugal com as Índias - especiarias, como sabemos, muito apreciadas na Europa. Assim, para equilibrar a conta de comércio entre Europa e Oriente, foram necessárias pesadas transferências de prata.

Inicialmente, Portugal obtinha prata em pequena monta, na Alemanha e em sua feitoria japonesa de Nagasaki. Mas, a partir da segunda metade do século XVI, as reservas portuguesas passaram a ser abastecidas com a prata obtida mediante o contrabando de produtos e escravos para a região da Prata, esta atingida pelos "fundos do seu quintal": o Rio da Prata. A cidade do Rio de Janeiro funcionava, então, como base logística para essa atividade, pelas vantagens da rota Rio-África em relação à rota Nordeste-África. Assim, o Rio de Janeiro passou a ser um entreposto entre duas rotas. A primeira ligava a cidade à Europa, Ásia e África, para a exportação de produtos como açúcar, tabaco e farinha de mandioca e a importação de especiarias das Índias, produtos europeus e, sobretudo, escravos africanos. A segunda rota ligava o Rio de Janeiro à América Espanhola e ao Rio da Prata, para o contrabando de escravos e mercadorias em troca da prata. Portanto, o Rio de Janeiro, mesmo antes do ciclo do ouro e de tornar-se a Capital Federal do Brasil, assumiu um papel central no território brasileiro, por sua origem de porto e fortificação militar. A riqueza gerada para Portugal, a partir do comércio da prata, seria sucedida pelo comércio com o ouro de Minas Gerais, reafirmando o status da cidade do Rio de Janeiro como eixo logístico nacional. Como expôs Lessa (2000a:125): "Com o controle fiscal das minas de ouro e a posição forte e crescente no núcleo de tráfico negreiro, deriva-se e reforça-se a hegemonia o Rio".

Ademais, a centralidade do Rio de Janeiro também se acentuou pelo fato de, paralelamente ao comércio exterior (sua principal atividade), ter-se desenvolvido, durante o século XVIII, o comércio colonial de cabotagem, que trocava escravos por fumo baiano e por carne-seca e banha do sul do país. Ao mesmo tempo, com o Planalto Central, a cidade do Rio articulou-se como praça atacadista, vendendo escravos, alimentos e manufaturas importadas e recebendo pagamentos em ouro e diamantes. Em suma, novamente recorrendo a Lessa (2000a:33): "o Rio colonial foi o epicentro desta complexa rede de relações comerciais. Era uma vila modesta, em termos demográficos, porém uma forte praça comercial e marítima".

30 assunto é examinado mais detalhadamente em Lessa (2000a) e em Osorio (2005). 


\section{Cultura e autoestima}

A centralidade do Rio de Janeiro no cenário brasileiro reafirmou-se, em 1763, quando da transferência da capital do Brasil de Salvador para o Rio, o que ocorreu pela necessidade de a Coroa Portuguesa garantir maior controle sobre a riqueza gerada com a produção do ouro em Minas Gerais. Na nova capital, a Corte de D. João VI se instalou, em 1808, implantando, segundo Lessa (2000a:63 e 77), "os signos capitalinos" da cidade e recebendo "um choque autônomo 'keynesiano', ${ }^{4}$ um presente de Napoleão: a Família Real e mais 15 mil portugueses. Essa incorporação acontece numa vila colonial com população estimada entre 43 e 50 mil pessoas".

Assim, com a vinda da Família Real para o Brasil, a cidade do Rio foi beneficiada com investimentos de proporções extraordinárias. D. João VI agregou institucionalização formal e informal à vida colonial, com a criação de tribunais, conselhos, câmaras, de instituições encarregadas do ordenamento e policiamento da cidade, de cursos de Direito etc., além da criação do primeiro Banco do Brasil do país. A questão era equipar a cidade para a função de sede da Corte Portuguesa e, para tanto, foram criados vários órgãos administrativos e de caráter jurídico. Ao mesmo tempo, afirmava-se o projeto civilizador da monarquia, de inspiração europeia. Instituições culturais e prestigiados espaços urbanos, como o Jardim Botânico, foram edificados no suceder dos anos. Constituiu-se a Real Biblioteca de Língua Portuguesa, atual Biblioteca Nacional, sendo abertas várias livrarias na cidade. Em 1818, D. João VI fundou o Museu Real, hoje Museu Nacional, localizado na Quinta da Boa Vista.

Em 1813, foi inaugurado o Teatro Real de S. João, em estilo neoclássico, à semelhança do Teatro de São Carlos, de Lisboa, e forte apoio foi dado à realização de recitais de música erudita e peças teatrais. Mais: D. João VI tornou-se grande incentivador do estudo formal das Belas Artes, inclusive contratando a vinda ao Brasil da Missão Artística Francesa, em 1816, que contava com integrantes de renome, como o arquiteto Grandjean de Montigny. Vários projetos arquitetônicos seriam então realizados para a cidade, divulgando o neoclassicismo em fachadas e arcos triunfais que deram ao Rio características de uma capital europeia. ${ }^{5}$ Paralelamente, a partir do movimento diário de seu porto, o Rio de Janeiro incorporava influências culturais e hábitos europeus.

Dessa forma, a história pregressa de porto e de eixo de logística nacional, a transferência da capital de Salvador para o Rio de Janeiro, em 1763, e o "choque de modernização" com a chegada da Família Real consolidavam a cidade do Rio de Janeiro como o eixo da capitalidade brasileira. ${ }^{6}$

Progresso e civilização foram palavras de ordem do poder monárquico e republicano até o início do século XX. Não por acaso, já nos primeiros anos do século XX o presidente Rodrigues Alves (1902-1906) elaborou um plano para realização de ampla reforma, saneadora e modernizante, na cidade do Rio de Janeiro - a capital da República -, reforma esta que ficou conhecida como "Bota Abaixo!" e "Rio Civiliza-se" e que buscou remover do centro carioca os vestígios de uma cidade colonial. O objetivo era remodelar e higienizar o centro da cidade, transformando-o em um "cartão de visitas". Sob a direção do ministro da Indústria, Viação e Obras Públicas, Lauro Muller, foram construídas a Avenida Central (atual Avenida Rio Branco) e a Avenida do Mangue (hoje o trecho da Avenida Presidente Vargas desde a Praça Onze até a Avenida Francisco Bicalho), e também um cais para o porto do Rio de Janeiro. Ao mesmo tempo, importante conjunto de obras foi empreendido pelo prefeito da cidade, Pereira Passos, operadas em velocidade extraordinária e que transformaram definitivamente a paisagem da capital federal. As ruas mais movimentadas do centro foram alargadas e espaços públicos higienizados. Quiosques, casas populares e cortiços foram derrubados. Becos e ruelas escuras deram lugar a iluminadas e largas avenidas, com lojas, cinemas e cafés elegantes, que iriam constituir então os novos símbolos nacionais de civilização e progresso.

4 "Choque autônomo keynesiano" é uma expressão usada pelos economistas quando ocorre uma "injeção" de gastos em determinada economia, dinamizando-a.

5 As transformações na cidade do Rio, com a vinda da Corte Portuguesa para o Brasil, são apresentadas em Versiani (2007).

60 assunto é desenvolvido também em Motta (2000 e 2001). 
O padrão de civilização almejado destruiu a feição pobre e insalubre da área central da cidade. Contudo, os populares que ali residiam não foram beneficiados com o projeto, sendo desalojados e obrigados a mudar-se para locais distantes ou a engrossar a população favelada.

No correr dos anos, a importância do Rio de Janeiro no cenário da cultura prestigiada nacional afirmou-se mais e mais, expresso em enorme patrimônio acumulado, na cidade e também no conjunto do estado, que abrigam importantes universidades e centros de excelência nas áreas de documentação e de preservação e pesquisa, públicos e privados. $\mathrm{Ou}$ seja, o Rio de Janeiro, como espaço de prosperidade da cultura nacional, ainda é uma realidade, com ricas e heterogêneas produções e manifestações artísticas, da música ao cinema e à fotografia, da arquitetura às artes plásticas, do desenho à caricatura, do teatro à literatura, da dança ao carnaval e muito mais.

E se a importância cultural do Rio no conjunto do país, dentro dos padrões europeus, foi em muito consolidada com a vinda da Família Real, pode-se dizer que a partir do século $\mathrm{XX}$ esse cenário de mimetismo começou a se alterar, dando lugar à valorização das especificidades do país.

Emblemático desse processo, nas primeiras décadas do século XX surgiu todo um conjunto de obras promovendo grande valorização da cultura nacional e regional, com autores como Euclides da Cunha (Os sertões, 1902), Monteiro Lobato (Urupês, 1918), Oswald de Andrade (Manifesto Pau-Brasil, 1924), Mário de Andrade (Macunaíma, 1928), Jorge Amado (O país do carnaval, 1931), Gilberto Freire (Casa-grande e senzala, 1933), Sérgio Buarque de Holanda (Raízes do Brasil, 1936), Roberto Simonsen (História econômica do Brasil, 1937), Graciliano Ramos (Vidas secas, 1938) e Guimarães Rosa (Grande sertão: veredas, 1956). No correr do mesmo período, figurariam também expressões críticas a um "falso nacionalismo", bem expressas nos trabalhos de vanguarda de toda uma geração de artistas, músicos e escritores modernistas que propunham a "devoração cultural" das técnicas importadas, tendo em vista reelaborá-las, com autonomia, e convertê-las em produtos de exportação. De acordo com Carlos Lessa (2000b:41-43):

Ao estudar a Europa no pós-guerra, os intelectuais brasileiros viram Picasso fazendo cubismo pela adoção dos modelos da arte africana; viram Miró acolhendo a estética da arte dos esquimós; viram os europeus de vanguarda questionando a cultura europeia, alguns jogando seus paradigmas na lata do lixo. Isto os impressionou. Para valorizar nossas influências etnográficas, Anita Malfati, Portinari, Di Cavalcanti e Tarsila não precisavam procurar os esquimós: bastava reler as lendas brasileiras, captar as cores, olhar os sujeitos sociais. O Brasil era um contingente a desbravar. Menotti Del Picchia vai procurar a linguagem caipira. Villa Lobos vai ouvir o choro, as modinhas mineiras, os ritmos do Nordeste, os sons da Amazônia. [...] Resgata-se o barroco colonial, por mais que os franceses da Missão Artística tivessem dito que o barroco brasileiro não valia nada. [...] A intelectualidade brasileira extrai desse percurso uma constatação: 'se eu valorizo a produção cultural desse povo, então esse povo é genial'. E qual é a cor do povo brasileiro? O povo brasileiro é furtacor. Vai do preto ao branco, passando por todas as gradações intermediárias - sendo preferencialmente o intermediário. Di Cavalcanti vai dizer que o símbolo sexual, a beleza do Brasil, é a mulata. O samba vai valorizar e romantizar a cultura popular. [...] A capoeira deixa de ser caso de polícia: é uma forma corporal de expressão artística. [...] Há uma explosão do folclore, o Brasil deslumbra-se consigo mesmo.

O que se propunha era a reinvenção cultural da nação, em relação ao que a cidade do Rio de Janeiro exerceu um papel insofismável, seguindo até hoje como espaço prestigiado da cultura nacional, inclusive mantendo-se como a principal referência externa do país.

Tal valorização da cultura nacional e regional articula-se a uma ampliação da autoestima no país influenciada por fatores históricos e políticos. Carlos Lessa (2000b:40-41) aponta:

A Primeira Guerra Mundial dissolveu o fascínio dos brasileiros pela Europa. Afinal o Velho Mundo havia praticado, por razões geopolíticas, matanças em escala industrial. O Brasil estava no Novo Mundo, no qual despontavam os Estados Unidos como polo mundial. Havíamos consolidado um imenso território, definindo pacificamente nossas fronteiras com os vizinhos: a combinação da velha astúcia portuguesa, da ousadia dos bandeirantes e da competência dos nossos diplomatas havia produzido um feito geopolítico até hoje pouco avaliado. 
Nesse cenário, a eficiência, do Barão do Rio Branco no exercício da diplomacia brasileira contribuiu para a valorização dos feitos nacionais. O Barão, ou José Maria da Silva Paranhos Júnior, liderou a resolução de disputas do Brasil com o Uruguai e a França pelos territórios, respectivamente, de Sete Povos das Missões e do Amapá, áreas nas quais o governo brasileiro garantiria o seu domínio. Em 1902, Rio Branco assumiu o Ministério das Relações Exteriores (1902-1912) e, entre as importantes ações de sua chancelaria, teve destaque a incorporação do Acre - originalmente parte da Bolívia - ao território brasileiro.

Nesse contexto da primeira metade do século XX, o Brasil modernizou-se e a cidade do Rio de Janeiro manteve a sua centralidade. Consolidou-se como um local querido de referência para todos os brasileiros. Não por acaso tornou-se também o território onde o samba e a marchinha popularizaram-se e em que teve início a chamada época de ouro da música popular brasileira, com a chegada do rádio ao país. Constituiu ainda o lugar central onde surgiram movimentos referenciais como a Bossa Nova e o Cinema Novo, entre outros projetos/criações inovadores no mundo cultural brasileiro.

Nesse cenário, que tem como auge os chamados "anos dourados", o Rio reforça o seu lugar de principal referência externa do país e de eixo da capitalidade brasileira.

\section{Reflexos da história de capital e de capitalidade na economia do Rio de Janeiro}

Do ponto de vista demográfico e econômico, a cidade e o estado do Rio de Janeiro, sobretudo até os anos 1920, também apresentaram enorme centralidade no país. De acordo com o Censo de 1872, por exemplo, a cidade possuía 274.972 habitantes, contra apenas 31.385 habitantes na cidade de São Paulo, hoje a mais populosa cidade brasileira. Esses números são expressivos, sobretudo se levarmos em conta que em 2013, de acordo com estimativas do IBGE, a cidade do Rio possuía 6.429.922 habitantes e a cidade de São Paulo 11.821.876 habitantes.

Até a realização do Censo Industrial de 1919, o conjunto da cidade e do estado do Rio ${ }^{7}$ apresentava o maior PIB industrial do país, inclusive superior ao do estado de São Paulo (Osorio, 2005:265). O dinamismo dessa região derivava então:

1. do capital mercantil gerado com a estrutura portuária na cidade do Rio;

2. da transferência da capital para o Rio, em 1763;

3. da vinda da Família Real para a cidade, em 1808, e consolidação do Rio como eixo da capitalidade brasileira; e

4. da exploração do açúcar e do café financiada pelo capital mercantil acumulado na cidade.

Sobre a articulação econômica entre a cidade e o estado do Rio, Carlos Lessa (2000a:61) pontua: "O engenho açucareiro fluminense foi um desdobramento comercial e financeiro do capital mercantil ligado ao comércio com a região do Prata e com a África. No século XIX, a plantação cafeeira tem um capítulo inicial essencialmente urbano".

A cidade do Rio de Janeiro de fato desenvolveu-se, como vimos, como o epicentro de um sistema de articulação e distribuição nacional, concentrador da renda e de serviços. Nela, sempre havia espaço e possibilidades para a diversificação das atividades produtivas, posto que os trabalhos logísticos abriam tais possibilidades de expansão. Vale citar:

70 atual território do estado do Rio de Janeiro, até 1960, compunha-se de duas unidades federativas: 0 antigo Distrito Federal e o antigo estado do Rio de Janeiro, este também chamado de 'Velha Província'. Com a mudança da Capital Federal para Brasília, em 1960, a cidade do Rio de Janeiro passou a constituir a cidade-estado Guanabara. Em 1974, como sabemos, ocorreu a fusão entre a Guanabara e a Velha Província, sendo criado o atual estado do Rio de Janeiro. Por esse motivo, ao compararmos o Rio de Janeiro com outros estados brasileiros, em períodos anteriores a 1974, realizamos sempre o somatório dos dados da economia da cidade do Rio com a economia do antigo estado do Rio de Janeiro. 
[Na cidade do Rio] desenvolvem-se e localizam-se os serviços para o conjunto das cidades integradas na rede. Estrutura-se a presença do artesanato sofisticado e surge uma poeira de ensaios manufatureiros. Na medida em que progride o crescimento urbano, a troca mercantil se amplifica, prossegue a diferenciação dos processos de divisão do trabalho. A cidade pôde crescer e não ser sede de processo de industrialização. Ao se constituir no coração de uma rede, ela promove e intermedeia transações e acumula ganhos mercantis. (Lessa, 2000a:125)

Portanto, a produção cafeeira e açucareira no antigo estado do Rio era um desdobramento do agente mercantil e constituía a retaguarda mediata do porto. Assim, é um equívoco atribuir ao açúcar e ao café a indução dinâmica do estado do Rio de Janeiro, nos seus períodos áureos:

A relação ... é inversa. O café não surgiu apenas fisicamente no interior do Rio. Foi financiado pelo capital mercantil do grosso comércio do Rio e deu continuidade à sua prosperidade. A cidade explica o prodígio do café escravo. (Lessa, 2000a:128)

A partir de 1919, o conjunto da cidade e do estado do Rio de Janeiro perdeu a sua hegemonia econômica para o estado de São Paulo (Osorio, 2005:265). No entanto, entre 1920/1960 o dinamismo carioca se manteve próximo ao da média nacional, em um período em que, de acordo com dados do Ipea/Data, o Brasil apresentou forte crescimento do PIB, de em torno de $5,7 \%$ ao ano. Isso se deveu ao fato de que, embora perdendo continuamente posição relativa no cenário industrial da economia brasileira, o então Distrito Federal - como sede do poder, eixo da capitalidade brasileira e como espaço concentrador de renda e capacidade de consumo - continuou a atrair e gerar investimentos públicos e privados.

Assim, indicadores relativos ao PIB dos estados e regiões do Brasil, por exemplo, apontam que, nos anos 1950, o território que abrange o conjunto da atual região fluminense apresentou um crescimento médio percentual de 6,6\% ao ano, bastante próximo ao da Região Sudeste, de 6,7\% ao ano, e ao total do Brasil, de 7,1\% ao ano (Pacheco, 1998:69).

Carlos Lessa (2000a:237-238) analisa essa questão da seguinte forma:

As décadas de 1920 a 1960 foram de prosperidade e de acumulação de prestígio no Rio de Janeiro. A cidade desdobrou-se em novos comportamentos e dimensões. (...) O Rio urbanizou-se em sintonia com esses novos tempos. Cabe sublinhar que foi sendo secundarizado, em termos de produção industrial, em relação a São Paulo. Desde a Primeira Guerra Mundial, São Paulo lidera a produção industrial e, apesar de crescer, o Rio vê a distância relativa das respectivas bases industriais ser ampliada, para não lembrar a espantosa diferença no campo agrícola. Porém o Rio - concentrando serviços sofisticados, com o núcleo de comando do sistema bancário, sediando os escritórios centrais da maioria das grandes empresas, sendo o portal dos visitantes nacionais e estrangeiros e alimentado por contínuas e crescentes injeções de gasto público - parecia ter assinado um pacto com a eterna prosperidade.

Ou seja, no período entre 1920 e 1960, a economia do Rio de Janeiro, ao contrário de depender apenas dos gastos públicos da chamada administração direta e de uma atividade mercantil tradicional, beneficiou-se também, por exemplo: da criação de empresas estatais em seu território; de ser sede da Bolsa de Valores e o principal centro financeiro do país; de sediar o núcleo de comando de grupos econômicos nacionais e internacionais, em um momento em que o Brasil se modernizava, deixava de ser rural para ser urbano e se industrializava; e do crescimento, em seu território, do turismo de negócios e de lazer e de atividades vinculadas à economia da cultura. Deve-se lembrar ainda que a criação de empresas estatais no Rio de Janeiro contribuiria também para atrair sedes de empresas privadas, que não atuavam somente no território carioca e fluminense.

Entre outros, foram criados na cidade do Rio: o Banco Nacional de Desenvolvimento Econômico (1952); a Petróleo Brasileiro S/A - Petrobras (1953); a Empresa Mista Centrais Elétricas Brasileiras SA - Eletrobras (1962); e a Companhia Vale do Rio Doce (1942). No campo científico e cultural, foram criados: o Instituto Nacional de Tecnologia - INT (1921); o Departamento Nacional de Produção Mineral - DNPM (1934); a Universidade do Brasil (1937); o Intituto Brasileiro de Geografia e Estatística - IBGE (1937); o Instituto Nacional de 
Matemática Pura e Aplicada - IMPA (1952); o Instituto Militar de Engenharia - IME (1959); o Museu Histórico Nacional - MHN (1922); o Museu Nacional de Belas Artes - MNBA (1937); e o Museu de Arte Moderna - MAM (1948). Ademais, instituições existentes desde o século XIX na cidade do Rio de Janeiro se fortaleceram, como o Banco do Brasil e a Caixa Econômica Federal.

Já o antigo estado do Rio de Janeiro - considerado por Lysia Bernardes (1964) uma região polarizada pela cidade do Rio de Janeiro do ponto de vista econômico - beneficiava- se da proximidade do mercado consumidor da capital da República e também foi cenário de investimentos federais, como a instalação da Companhia Siderúrgica Nacional (1941); da Fábrica Nacional de Motores (1942); da Companhia Nacional de Álcalis (1943) e da Refinaria Duque de Caxias (1961), investimentos estes cujas decisões locacionais estiveram relacionadas à proximidade da antiga Capital Federal e, junto, à existência de uma tendência dominante no governo central a favor de que então se estabelecesse um contraponto no país ao predomínio econômico paulista (Lessa, 2000:346).

Desse modo, principalmente até 1960, o estado do Rio de Janeiro como um todo derivou o seu dinamismo econômico de quatro vetores: o dinamismo da economia brasileira; a centralidade da cidade do Rio, pela sua história de eixo logístico e de capitalidade; o fato de a cidade ser o núcleo do poder nacional; e os investimentos estatais produtivos realizados no antigo estado do Rio.

\section{Consequências, no pós-1960, da trajetória nacional do Rio}

A partir de 1960, com a transferência da capital para Brasília, principalmente a partir dos anos 1970, com a consolidação dessa transferência, a cidade do Rio de Janeiro e o antigo estado do Rio de Janeiro passaram a apresentar um processo de perda de participação na economia nacional, tendo em vista a importância do gasto público e dos investimentos federais para o dinamismo econômico do conjunto da região. Entre 1970 e $2011,{ }^{8}$ de acordo com dados do IBGE, o estado do Rio de Janeiro apresentou a maior perda de participação no PIB nacional entre todas as unidades federativas, de $-33,2 \%$. Nesse período, a participação da economia fluminense no PIB nacional passou de 16,7\%, em 1970, para 11,2 \%, em 2011. Na mesma direção, a economia da cidade do Rio de Janeiro apresentou a maior perda de participação no PIB nacional, entre todas as capitais dos estados brasileiros, de -60,64\%. Nesse período, a participação da economia carioca no PIB nacional passou de 12,84\%, em 1970, para 5,05\%, em 2011.

Na mesma direção, de acordo com os dados sobre emprego formal constantes da Relação Anual de Informações Sociais/Ministério do Trabalho e Emprego - RAIS/MTE, entre 1985 e 2012 - série mais longa com a mesma metodologia -, o estado do Rio apresentou um crescimento do emprego formal de apenas $66,9 \%$, contra um crescimento expressivamente maior no total do país, de $131,6 \%$. Na indústria de transformação, nesse período, o estado do Rio de Janeiro apresentou uma queda do emprego formal, de $-10,7 \%$, contra um crescimento no país de 56,3\%. Tanto no total de atividades econômicas quanto na indústria de transformação, o crescimento do emprego formal no estado do Rio foi o menor entre todas as unidades federativas brasileiras.

Mesmo no setor serviços, que tem forte importância na economia fluminense, inclusive por sua história de capitalidade, o crescimento do emprego formal no estado do Rio também foi, no mesmo período, o menor entre todas as unidades federativas, de apenas 92,8\% contra um crescimento no total do Brasil de $167,3 \%$.

Junto com a transferência da capital para Brasília, contribuiu também para a decadência econômica da cidade do Rio de Janeiro e do conjunto do estado no cenário nacional o fato de os cariocas e fluminenses só terem se dado conta das consequências da mudança da capital a partir da década de 1980, no bojo da crise econômico-fiscal que então se instaurou

8 Como dito, em 1974 ocorreu a fusão entre o antigo estado do Rio de Janeiro e a então Guanabara, formando-se o atual estado do Rio de Janeiro, com a cidade do Rio como sua capital. Por esse motivo, ao ser comparado o peso da economia do estado do Rio de Janeiro, no Brasil, entre 1970 e 2010 usou-se, para o ano de 1970, o somatório dos PIBs carioca e do antigo estado do Rio. 
no país, a partir do segundo choque do petróleo e da brutal elevação das taxas de juros na economia internacional. O Brasil foi atravessado por profunda estagnação econômica, que atingiu particularmente o estado do Rio de Janeiro. ${ }^{9}$

A demora na percepção das consequências para o Rio da mudança da capital tem relação, por um lado, com o fato de que a transferência da capital ocorreu de forma lenta, só se consolidando nos anos 1970. Além disso, o forte dinamismo econômico ocorrido no Brasil, entre 1968 e o final da década de 1970, "mascarou" o processo de perda já em curso. ${ }^{10}$

Por outro lado, essa demora de percepção deveu-se, em grande medida, à história de capitalidade da cidade do Rio de Janeiro, fazendo com que, mesmo até os dias atuais, os hábitos e as atenções sociais nela construídos voltem-se fundamentalmente para a temática nacional. Arnaldo Niskier, em trabalho denominado Rio Ano 2000, pontuou essa questão afirmando que o fato de a história da cidade de São Sebastião ter, durante quase dois séculos, se confundido muitas vezes com a história brasileira teria feito com que a vivência dos problemas nacionais, no Rio, reduzisse quaisquer problemas locais a "pálidos reflexos dos problemas nacionais. [Assim,] depois da mudança da capital para o Planalto, o povo carioca descobriu que só conhecia de si mesmo e de sua cidade a visão do turista apressado" (Guanabara, 1970:15).

As permanências, fruto de uma determinada cultura e história, podem ser analisadas utilizando-se o conceitual teórico do economista institucionalista Douglass North (1993), quando ele afirma que uma determinada conformação institucional cria hábitos e rotinas arraigados, nos quais as questões de escolha se apresentam como algo regular, repetitivo e evidente, de modo que cerca de $90 \%$ de nossas ações em vida são realizadas de forma basicamente automática.

No mesmo sentido, Geoffrey M. Hodgson (1997), partindo de pressupostos teóricos distintos desenvolvidos por autores como Marx, Keynes e os institucionalistas americanos do final do século XIX e início do XX - Veblen, Commons e Mitchell ${ }^{11}$-, chega a conclusões, sobre a questão da dinâmica institucional, bastante próximas às construídas por North, ${ }^{12}$ conforme se pode deduzir da seguinte passagem:

[Veblen] observou que as instituições têm uma qualidade de estabilidade e inércia e que tendem a manter e, portanto, a 'transmitir' as suas características importantes ao longo do tempo. As instituições são consideradas frutos e reforçadores dos processos de pensamento rotinizados, sendo partilhadas por um conjunto de pessoas numa dada sociedade. (Hodgson, 1997:276)

Geoffrey Hodgson afirma também que o institucionalismo compreende os indivíduos a partir do modo como estão situados e envolvidos em seu mundo social. Dessa forma, as suas funções e preferências não seriam dadas e fixas, mas sim construídas e reconstruídas socialmente, em um contínuo processo de adaptação e mudanças. Novamente citando Veblen, Hodgson (1997:10) escreve:

Uma linha de ação habitual constitui uma linha habitual de pensamento e dá o ponto de vista através do qual os fatos e eventos são apreendidos e reduzidos a um corpo de conhecimento. As instituições criam e reforçam os hábitos de ação e pensamento: a situação de hoje molda as

9 A crise que se instalou no país a partir dos anos 1980, com a mudança do cenário internacional no final da década de 1970, afetou pesadamente a capacidade de gasto do poder público no Brasil. Como, no final dos anos 1970, a presença de instituições governamentais na cidade do Rio de Janeiro ainda era muito forte, a crise econômico-fiscal atingiu a região de forma mais significativa do que as demais regiões brasileiras.

10 Em 1964, o governo constitucional de João Goulart foi derrubado pelos militares, com apoio de setores políticos e da sociedade civil, instaurando-se, no Brasil, uma ditadura militar que sobreviveu até os anos 1980. Um dos fatores que possibilitaram o êxito do golpe foi o fato da economia brasileira, ao contrário do que havia ocorrido entre 1930 e 1960, ter parado de crescer e ter ainda ocorrido uma for te elevação inflacionária a par tir do início dos anos 1960, sendo que, às vésperas do golpe militar, em março de 1964, a inflação brasileira era de em torno de $80 \%$ ao ano. 0 primeiro governo militar (1964-1967) conseguiu lograr uma série de mudancas institucionais no país, conhecida como "modernizacão conservadora", que, ao lado de um cenário internacional de baixas taxas de juros, permitiu que o país voltasse a ter, entre 1968 e o final dos anos 1970, um alto crescimento anual do PIB. Sobre o assunto, ver Castro e Souza (1985); Gaspari (2002a, 2002b e 2003) e Lacerda (2000).

11 Geoffrey Hodgson utiliza como referência básica os institucionalistas americanos citados. No entanto, em sua obra aparece com centralidade os trabalhos de Veblen quando este propõe que se troque, como paradigma econômico, a ideia de equilíbrio advinda da Física pela ideia de evolução, utilizando a Biologia como metáfora.

12 A questão da existência de aspectos heterodoxos na formulação de Douglass North é pontuada em Fiani (2003). 
instituições de amanhã, através de um processo coercivo e seletivo, através da ação sobre a visão habitual do homem das coisas e dessa forma alterando ou fortificando um ponto de vista de uma atitude mental trazida do passado. ${ }^{13}$

É nessa perspectiva que se pode aferir que a cultura de capitalidade do Rio de Janeiro acaba por contribuir para que nessa região demorasse a ocorrer a percepção da quebra da dinâmica institucional, a partir de um fator "exógeno" (a mudança da Capital Federal para Brasília, em 1960).

A particular preocupação, no estado do Rio de Janeiro, com os temas nacionais vis-à-vis os locais, presente até os dias de hoje, pode ser verificada, por exemplo, pelo fato de que, se entrarmos nos sites dos Programas de Mestrado e Doutorado em Economia das Universidades localizadas na Região Metropolitana do Rio de Janeiro, veremos que permanecem inexistindo programas de pesquisa oficiais permanentes em Economia Regional. Isto ao contrário do que ocorre em outras regiões brasileiras, como São Paulo e Minas Gerais.

Por último, deve-se ainda destacar que também contribuiu para a falta de dinamismo econômico e perda de participação do estado do Rio de Janeiro na economia nacional, o golpe de 1964 e subsequentes cassações de mandatos, que atingiram a cidade do Rio de Janeiro com particular gravidade, pela forte presença de seus parlamentares no debate nacional. As cassações, no Rio, atingiram a esquerda e a direita, abrindo espaço para a hegemonia de Chagas Freitas, na Guanabara e depois em todo o estado do Rio, gerando uma lógica particularmente clientelista, que desestruturou a área pública no estado, afetando a capacidade de planejamento e de políticas de indução ao fomento econômico. ${ }^{14}$

\section{O Rio de Janeiro no século XXI: mudanças, oportunidades e capitalidade}

Nos últimos anos, o estado do Rio de Janeiro deixou de "afugentar" investimentos e passou a reter os existentes e a atrair novos. Isso está relacionado com o início de uma reestruturação da máquina pública no estado, bem como com potencialidades em torno do complexo de petróleo e gás e da política de conteúdo nacional desenvolvida pelo governo federal. Está viabilizando, por exemplo, um crescimento do setor naval de em torno de $19,5 \%$ ao ano, entre 2000 e $2010 .{ }^{15}$

No entanto, do ponto de vista do estabelecimento de uma rotina de planejamento e coordenação de políticas, que dê conta, concomitantemente, do pleno aproveitamento das possibilidades existentes no horizonte, a partir do ciclo de investimentos que já chegam ao estado ou estão previstos e do enfrentamento dos graves problemas e desigualdades que ainda perduram no campo econômico-social e de infraestrutura no estado do Rio de Janeiro, os desafios ainda se encontram em aberto.

Nesse sentido, a afirmação de uma cultura de planejamento para o desenvolvimento regional é fundamental. Do ponto de vista econômico, deve-se priorizar, em uma estratégia de planejamento, entre outras atividades, aquelas em que o Rio de Janeiro, por sua histórica de capitalidade, apresenta potencialidade.

O setor serviços apresenta forte centralidade na economia do estado do Rio e principalmente da cidade, que deriva, dentre outros fatores, da sua história de capitalidade. Nesse setor estão todas aquelas atividades que não estão incluídas entre as atividades agroindustriais e industriais. Assim, é importante procurar verificar quais são as atividades dentro do conjunto do setor serviços que podem ter capacidade indutora para ampliação do dinamismo econômico na região. Ou seja, aquelas atividades que podem atender não só ao mercado consumidor existente na cidade e no estado do Rio, mas também a outras regiões brasileiras e ao exterior, atraindo renda e aumentando a densidade e as inter-relações da economia carioca e fluminense.

13 Tradução de Alexandre Borges.

14 Sobre esse assunto, ver Osorio; Versiani (2013).

15 A informação pode ser encontrada em matéria publicada no jornal Valor Econômico, de 27/5/2014, p. G6, intitulada "Setor naval cresce 19,5\% ao ano desde 2000. Estaleiros entregam quantidade recorde de embarcações, parte de programa de R\$149,5 bi". 
Em trabalho recente que fizemos para o Sebrae, denominado "A capacidade indutora dos serviços no estado do Rio de Janeiro" (Osorio; Sobral, 2013), definimos como "indutores" da economia da cidade e do estado do Rio os seguintes blocos de atividades: turismo; telecomunicações e informática; elaboração de projetos, pesquisa e certificação; editorial e audiovisual; cultura, arte e lazer; e atividades esportivas e de lazer. Esses blocos de atividades foram definidos não só em função de sua "capacidade exportadora", mas também pelo seu peso na economia regional e potencialidade. Deve-se ter em conta ainda que essas atividades apresentam sinergias entre si, o que potencializa a sua capacidade de indução.

No que diz respeito ao turismo, o estado do Rio de Janeiro e principalmente sua capital, por suas belezas naturais, diversidade de mar e montanha, história de capitalidade e afabilidade de sua população, constituem um locus privilegiado para o desenvolvimento de atividades vinculadas ao chamado turismo de convivência, preferido pelo turista que viaja buscando conhecer a cultura e o modo de vida de uma determinada região. Um nicho de atividade turística não só relevante, mas em crescimento no mercado internacional. Entre os apreciadores do turismo de convivência podemos incluir, por exemplo, profissionais liberais, pesquisadores e estudantes. Turistas com esse perfil não gostam dos produtos enlatados do turismo de massa (voos charters e pacotes) nem de destinações que são operadas como megaempreendimentos (resorts, parques temáticos etc.). Preferem pesquisar e construir o seu próprio plano de férias, considerando variáveis como: cultura, entretenimento e experiência; destinações onde a vida e a espontaneidade local não são totalmente desfiguradas pela indústria turística; locais com diversidade de ofertas culturais, artísticas, eventos, museus, em um raio territorial relativamente pequeno; a oportunidade de contato com pessoas e instituições locais, a ponto de se sentir quase como em casa; e, entre outros aspectos, descobrir a realidade que se esconde sob os clichês e estereótipos.

É claro que, para o pleno aproveitamento desse tipo de atividade turística no estado do Rio, é de fundamental importância o desenvolvimento de uma estratégia turística regional, com o aprimoramento e detalhamento, por exemplo, dos roteiros e produtos já existentes e a criação de novos nas diversas regiões de governo do estado do Rio de Janeiro. Além disso, particularmente para esse tipo de turismo é essencial melhorar a infraestrutura no estado do Rio e sobretudo na metrópole carioca, com ações como a consolidação da despoluição de Baía de Guanabara e a criação de uma rede de transporte público sobre trilhos de qualidade, que permita, por exemplo, o acesso de turistas à Zona Suburbana, e às suas escolas de samba e tradições culturais, e estabeleça um serviço de metrô que interligue o Aeroporto Internacional Tom Jobim ao centro histórico e à Zona Sul da cidade do Rio de Janeiro, onde se encontra a grande maioria da rede hoteleira carioca.

$\mathrm{Na}$ área de telecomunicações e informática, a cidade do Rio também possui potencialidade, não só pelo fato de a Embratel ter sido criada e desenvolvida na cidade, como também pela capacidade de crescimento que as atividades vinculadas à tecnologia de informação apresentam, principalmente no que diz respeito às suas possíveis inter-relações com a área de mídia, cinema e vídeo e pelas demandas que provêm do complexo de petróleo e gás para esse setor. Um exemplo é o uso já em curso pelo setor de cinema e vídeo de tecnologia desenvolvida para a visualização do fundo do mar, tendo em vista a extração de petróleo em águas profundas. Outro exemplo é o crescimento já verificado, na cidade do Rio, de atividades vinculadas ao desenvolvimento de programas de computador sob encomenda, principalmente demandados por empresas ligadas ao complexo do petróleo e gás.

A área editorial e audiovisual também possui particular potencialidade, tendo em vista a sua forte inter-relação com a história de capitalidade do Rio. Tal potencialidade deriva não só do fato de cerca da metade do emprego formal no país vinculado à televisão estar na cidade do Rio de Janeiro, pela hegemonia da cidade na atividade cinematográfica e pelo seu forte peso na produção de vídeos, mas também pela legislação recente de conteúdo nacional para a produção de vídeos, que permitirá vigoroso crescimento dessa atividade no Brasil, nos próximos anos. Dados divulgados pela RioFilme mostram que, desde 2011, o investimento em produção independente de TV no Brasil apresenta um crescimento superior a $80 \%$ ao ano.

$\mathrm{Na}$ área de cultura, arte e lazer, o Rio de Janeiro, mais uma vez por sua história de capitalidade, possui óbvia potencialidade. Entre as evidências, dados da Rais/MTE apontam que se, por um lado, a cidade do Rio possuía, em 2012, 27,2\% dos empregos formais existentes 
nas capitais do Sudeste, no que se refere ao conjunto total das atividades econômicas, já especificamente para o setor de cultura, arte e lazer, a participação da cidade do Rio atingiu expressivos 39,4\% do total de empregos formais existentes nas capitais do Sudeste nesse setor.

Para uma ainda maior dinamização desse conjunto de atividades, deve-se buscar a ampliação do planejamento e o aprimoramento de uma política cultural, que contemple a cidade do Rio de Janeiro e as demais regiões do estado. Além disso, devem-se buscar as sinergias existentes entre a área cultural e a área educacional e turística.

A esse respeito, cabe notificar que um instrumento que em muito pode contribuir para o desenho de uma política cultural é o Mapa da Cultura desenvolvido pela Secretaria de Cultura do governo do estado do Rio de Janeiro no ano de 2013 (http://mapadecultura.rj.gov. br/).

A música e o Carnaval estão certamente entre os maiores patrimônios culturais da cidade do Rio e uma política de apoio a esse patrimônio gera também sinergias com a atividade turística. Uma política que poderia ser adotada é a de buscar maior formalização das atividades vinculadas à economia do Carnaval. Veja-se, por exemplo, que atualmente a Prefeitura e a Rede Globo assinam contrato com as escolas de samba no primeiro semestre de cada ano. Por que não antecipar a realização do contrato para o fim do ano anterior, liberando os recursos em doze parcelas, com a diminuição da sazonalidade e maior possibilidade de contratação de profissionais com carteira assinada?

Outra política importante seria o apoio ao aprimoramento profissional, por exemplo para cenógrafos, roteiristas etc., que podem vir a trabalhar não só em atividades carnavalescas, mas também na área de cinema e vídeo e em áreas da cultura em geral.

A cidade do Rio também apresenta forte proeminência no campo dos serviços de elaboração de projetos, pesquisa e certificação, que congrega serviços relacionados às áreas de arquitetura e engenharia; design e decoração de interiores; testes e análises técnicas (como os vinculados ao complexo de petróleo e gás); e pesquisa e desenvolvimento experimental em ciências físicas e naturais e em ciências sociais e humanas.

A participação da cidade do Rio no total dos empregos formais existentes no conjunto dessas atividades, nas capitais do Sudeste, é de 34,3\%, em 2012, sendo que, especificamente em pesquisa e desenvolvimento experimental em ciências físicas e naturais, a participação da cidade do Rio de Janeiro atinge expressivos 61,9\%, pela presença em seu território de instituições como o Centro Brasileiro de Pesquisas Físicas-CBPF, o Centro de Pesquisas e Desenvolvimento Leopoldo Américo Miguez de Mello-Cenpes, a Fundação Oswaldo CruzFiocruz, o Centro de Pesquisas de Energia Elétrica-Cepel e as instituições de pesquisa vinculadas às Forças Armadas.

Por esse motivo, torna-se de todo oportuno desenvolver o mercado de engenharia básica de projetos na cidade do Rio de Janeiro, atendendo, por exemplo, as demandas da Petrobras para exploração do pré-sal, bem como as demandas geradas pela política de conteúdo nacional.

A potencialidade do setor de elaboração de projetos, pesquisa e certificação, a história universitária da cidade do Rio e as atratividades que oferece aos seus visitantes levam ainda ao fato de que, se, por um lado, a cidade de São Paulo apresenta vantagens comparativas para a realização de feiras empresariais, a cidade do Rio de Janeiro mantém notória tradição e expertise na realização de congressos e convenções científicas (Osorio; Sobral, 2013:84).

Por último, entre as atividades indutoras do setor serviços em que a cidade e o estado do Rio apresentam potencialidade, podemos destacar aquelas vinculadas às atividades esportivas e de lazer. Também nesse bloco de atividades, enquanto, no ano de 2012, a cidade do Rio de Janeiro apresentou uma participação de 27,2\% no total do emprego formal existente, em todas as atividades, nas capitais do Sudeste, já nas atividades esportivas e de lazer, a participação da cidade do Rio no total do emprego formal gerado nas capitais do Sudeste foi de expressivos $38,5 \%$.

Em relação à área de esporte e lazer, deve-se destacar que o estado do Rio de Janeiro possui regiões de mar e montanha muito aprazíveis para atividades nesse setor, em todas as estações do ano. Além disso, a realização de diversos megaeventos na cidade, desde o Panamericano, em 2007, e a construção subsequente de equipamentos esportivos, contribui para a potencialidade já existente e, também, traz a necessidade social de definição do uso permanente dos equipamentos esportivos criados, seja pela população local seja pela busca da realização de eventos nacionais e internacionais.

Deve-se, portanto, organizar um planejamento e um calendário de eventos esportivos 
que busquem transformar a cidade do Rio de Janeiro na "capital dos esportes" da América Latina. Com esse objetivo, cabe ainda buscar a constituição, no estado do Rio, de centros de treinamento de referência internacional, como o Centro de Treinamento da Seleção de Vôlei, no município de Saquarema.

\section{Considerações finais}

Para o entendimento da trajetória de perda de participação econômica carioca e fluminense no cenário brasileiro, nos séculos XX e XXI, entendemos que a demarcação mais importante é a década de 1960, quando ocorre a transferência da Capital Federal para Brasília.

Isto porque, se em 1920 de fato a atividade industrial no Estado de São Paulo passou a ser superior à do conjunto do atual estado do Rio de Janeiro e o estado paulista liderou, nas décadas seguintes, o desenvolvimento industrial brasileiro, não podemos ainda falar em uma situação de "crise" regional no Rio de Janeiro, pois o conjunto da cidade e do antigo estado do Rio continuou a apresentar um crescimento econômico próximo ao do país. Seja pelo gasto público gerado em função da presença da capital na cidade do Rio, seja pelo dinamismo econômico em boa medida derivado da história de capitalidade do Rio, seja ainda pelos investimentos realizados na criação de empresas estatais no antigo estado do Rio de Janeiro, pela proximidade com a capital e também pelo desejo do poder central de realizar um contraponto ao predomínio econômico do Estado de São Paulo.

Em nossa visão, para o entendimento da trajetória econômica da cidade e do estado do Rio de Janeiro, entre 1920 e 1960, deve-se dar ênfase ao fato de que, além da presença do capital mercantil na cidade do Rio, ela desenvolveu, por sua história de capitalidade, uma série de atividades econômicas no setor serviços que levaram à existência de atividades indutoras para além da atividade industrial e que influenciaram o dinamismo econômico no conjunto do estado.

Da mesma forma, se na década de 1980 a crise no estado do Rio de Janeiro fica mais evidente no contexto da crise econômico-fiscal nacional, esta já vinha se desenvolvendo desde 1960 e principalmente 1970, tendo em vista a mudança da capital do país para o Planalto Central.

Dar ênfase à história de capitalidade do Rio de Janeiro permite ainda questionar a tese, que permeia o debate na mídia regional, de que a falta de dinamismo regional deriva da história da cidade apenas como capital burocrática e da consequente ausência de "empreendedorismo".

Ou seja, em nosso entendimento, a demarcação temporal central para que se entenda a degradação socioeconômica ocorrida no estado do Rio de Janeiro é a década de 1960 e deve-se ter em conta que tal degradação deriva de um conjunto de fatores inter-relacionados, que são: a transferência da capital; a carência de reflexão e de construção de estratégias regionais adequadas; e o marco de poder específico instalado no Rio como consequência do golpe de 1964.

Estamos convencidos ainda de que, para entender a trajetória econômica do atual estado do Rio de Janeiro e para o desenho de políticas que levem à consolidação de um novo ciclo virtuoso no estado, é fundamental pesquisar a história de capitalidade da "cidade maravilhosa". É nesse sentido que, no momento de comemoração dos 450 anos de fundação da cidade do Rio de Janeiro, procuramos trazer o tema da capitalidade para a agenda de debates. 


\section{Referências bibliográficas}

ABREU, Alzira Alves de et al. (Coord.). Dicionário histórico-biográfico brasileiro. Rio de Janeiro: Ed. da FGV/CPDOC, 2001.

ARGAN, Giulio C. L'Europe des capitales. Genebra: Albert Skiras, 1964.

BERNARDES, Lysia Maria Cavalcanti (Coord.). 0 Rio de Janeiro e sua região. Rio de Janeiro: IBGE/ Conselho Nacional de Geografia, 1964.

CANO, Wilson. Raízes da concentraç̃o industrial em São Paulo. 4. ed. Campinas/SP: UNICAMP/IE, 1998

CASTRO, Antonio Barros de; SOUZA, Francisco Eduardo Pires de. A economia brasileira em marcha forçada. Rio de Janeiro: Paz e Terra, 1985. V. 32.

FERREIRA, Marieta de Moraes (Coord.). Rio de Janeiro: uma cidade na história. Rio de Janeiro: Ed. da FGV, 2000.

FIANI, Ronaldo. Estado e economia no institucionalismo de Douglass North. Revista de Economia Política, vol. 23, n. 2, abr./jun. 2003

GASPARI, Elio. A ditadura envergonhada. São Paulo: Companhia das Letras, 2002a.

A ditadura escancarada. São Paulo: Companhia das Letras, 2002b.

A ditadura derrotada. São Paulo: Companhia das Letras, 2003

GUANABARA. Secretaria de Ciência e Tecnologia.

Comissão do ano 2000. Rio Ano 2000. Rio de Janeiro, 1970.

HIRSCHMAN, Alberto. Estratégia do desenvolvimento econômico. Rio de Janeiro: Fundo de Cultura, 1958.

HODGSON, Geoffrey M. Economia e evolução: 0 regresso da vida à teoria econômica. Oéiras: Celta, 1997.

LACERDA, Antônio Corrêa de et al. Economia brasileira. Editora Saraiva, 2000

LESSA, Carlos. 0 Rio de todos os Brasis: uma reflexão em busca de auto-estima. Rio de Janeiro: Record, 2000a.
LESSA, Carlos. Auto-estima e desenvolvimento social. Rio de Janeiro: Garamond, 2000b.

MAGALHÃES, J.P.A. et al. Rio Século XXI: perspectivas e propostas para a economia fluminense. Rio de Janeiro: JB, 1991.

MAGALHÃES, Raphael de Almeida. Breve histórico sobre a estruturação física e econômica da cidade e sua região. [S.I.: s.n.], 2001. Texto mimeografado.

MOTTA, Marly Silva da. Rio de Janeiro: de cidade-capital a Estado da Guanabara. Rio de Janeiro: ALERJ: 2001.

Saudades da Guanabara. Rio de Janeiro: Ed. da FGV, 2000.

NORTH, Douglass C. Instituciones, cambio institucional y desempeño económico. México: Fondo de Cultura Económica, 1993.

OSORIO, Mauro. Rio nacional, Rio local: mitos e visões da crise carioca e fluminense. Rio de Janeiro: Editora SENAC RIO, 2005.

; SOBRAL, Bruno. A capacidade indutora dos serviços no estado do Rio de Janeiro.

Relatório de pesquisa. Sebrae/RJ, ago. 2013.

; VERSIANI, Maria Helena. 0 papel das instituicões na trajetória econômico-social do estado do Rio de janeiro. Cadernos do Desenvolvimento Fluminense, n. 2, p. 1-23, 2013.

PACHECO, Carlos Américo. Fragmentação da nação. São Paulo: UNICAMP/IE, 1998.

PRESTES FILHO, L.C. (coord.). Cadeia produtiva da economia do carnaval. Rio de Janeiro: E-papers, 2009.

ROSA, Luiz Pinguelli. Gás Natural: Situação atual e potencialidade no estado do Rio de Janeiro: Fórum de Reitores. Rio de Janeiro: Faperj, 1994. Texto mimeografado.

VERSIANI, Maria Helena. Padrões e práticas na política carioca: os deputados federais eleitos pela Guanabara em 1962 e 1970. Dissertacão de Mestrado. Rio de Janeiro: Universidade Federal do Rio de Janeiro/ Instituto de Filosofia e Ciências Socais/ Programa de PósGraduacão em História Social, 2007. 